\title{
Single photon ionization of van der Waals clusters with a soft x-ray laser: $\left(\mathrm{SO}_{2}\right)_{n}$ and $\left(\mathrm{SO}_{2}\right)_{n}\left(\mathrm{H}_{2} \mathrm{O}\right)_{m}$
}

\author{
F. Dong \\ Department of Chemistry, Colorado State University, Fort Collins, Colorado 80523 \\ and NSF ERC for Extreme Ultraviolet Science and Technology, Colorado State University, Fort Collins, \\ Colorado 80523 \\ S. Heinbuch and J. J. Rocca \\ Department of Electrical and Computer Engineering, Colorado State University, Fort Collins, \\ Colorado 80523 and NSF ERC for Extreme Ultraviolet Science and Technology, Colorado State University, \\ Fort Collins, Colorado 80523 \\ E. R. Bernstein ${ }^{\text {a) }}$ \\ Department of Chemistry, Colorado State University, Fort Collins, Colorado 80523 \\ and NSF ERC for Extreme Ultraviolet Science and Technology, Colorado State University, Fort Collins, \\ Colorado 80523
}

(Received 12 June 2006; accepted 11 August 2006; published online 20 October 2006)

van der Waals cluster $\left(\mathrm{SO}_{2}\right)_{n}$ is investigated by using single photon ionization of a $26.5 \mathrm{eV}$ soft $\mathrm{x}$-ray laser. During the ionization process, neutral clusters suffer a small fragmentation because almost all energy is taken away by the photoelectron and a small part of the photon energy is deposited into the $\left(\mathrm{SO}_{2}\right)_{n}$ cluster. The distribution of $\left(\mathrm{SO}_{2}\right)_{n}$ clusters decreases roughly exponentially with increasing cluster size. The photoionization dissociation fraction of $I\left[\left(\mathrm{SO}_{2}\right)_{n-1} \mathrm{SO}^{+}\right] / I\left[\left(\mathrm{SO}_{2}\right)_{n}^{+}\right]$decreases with increasing cluster size due to the formation of cluster. The metastable dissociation rate constants of $\left(\mathrm{SO}_{2}\right)_{n}^{+}$are measured in the range of $(0.6-1.5) \times 10^{4} \mathrm{~s}^{-1}$ for cluster sizes $5 \leqslant n \leqslant 16$. Mixed $\mathrm{SO}_{2}-\mathrm{H}_{2} \mathrm{O}$ clusters are studied at different experimental conditions. At the condition of high $\mathrm{SO}_{2}$ concentration $\left(20 \% \mathrm{SO}_{2}\right.$ partial pressure), $\left(\mathrm{SO}_{2}\right)_{n}^{+}$cluster ions dominate the mass spectrum, and the unprotonated mixed cluster ions $\left(\mathrm{SO}_{2}\right)_{n} \mathrm{H}_{2} \mathrm{O}^{+}(1 \leqslant n \leqslant 5)$ are observed. At the condition of low $\mathrm{SO}_{2}$ concentration $\left(5 \% \mathrm{SO}_{2}\right.$ partial pressure $)\left(\mathrm{H}_{2} \mathrm{O}\right)_{n} \mathrm{H}^{+}$cluster ions are the dominant signals, and protonated cluster ions $\left(\mathrm{SO}_{2}\right)\left(\mathrm{H}_{2} \mathrm{O}\right)_{n} \mathrm{H}^{+}$are observed. The mixed clusters, containing only one $\mathrm{SO}_{2}$ or $\mathrm{H}_{2} \mathrm{O}$ molecule, $\mathrm{SO}_{2}\left(\mathrm{H}_{2} \mathrm{O}\right)_{n} \mathrm{H}^{+}$and $\left(\mathrm{SO}_{2}\right)_{n} \mathrm{H}_{2} \mathrm{O}^{+}$are observed, respectively. (C) 2006 American Institute of Physics. [DOI: 10.1063/1.2348878]

\section{INTRODUCTION}

Sulfur dioxide emissions from combustion, coal treatment, and volcanos can form acids in the atmosphere that return to earth in the form of acid depositions or "acid rain." Acid rain is one of the biggest environmental problems at present. Sulfur dioxide is the major contributor to acid rain and a generator of soot. The process of $\mathrm{SO}_{2}$ and water forming acid rain has been studied for some time in order to determine the atmospheric mechanism for this environmental issue. $^{1,2}$

The $\mathrm{SO}_{2}$ monomer and dimer have been extensively studied. Erickson and $\mathrm{Ng}^{3}$ measured the photoionization efficiency curves for $\mathrm{SO}_{2}$ and $\left(\mathrm{SO}_{2}\right)_{2}$ with high resolution in the wavelength region of $62.5-100.5 \mathrm{~nm}$. The ionization energies (IEs) of $\mathrm{SO}_{2}$ and $\left(\mathrm{SO}_{2}\right)_{2}$ are determined to be 12.35 and $11.72 \mathrm{eV}$, respectively. Taleb-Bendiab et al. ${ }^{4}$ investigated the microwave spectroscopy of $\left(\mathrm{SO}_{2}\right)_{2}$. The structure of the $\mathrm{SO}_{2}$ dimer is low symmetry in which one $\mathrm{SO}_{2}$ unit defines a plane and the second $\mathrm{SO}_{2}$ unit lies above the first, with its two $\mathrm{O}$ atoms straddling the first $\mathrm{SO}_{2}$. The two planes containing the $\mathrm{SO}_{2}$ molecules are perpendicular to each

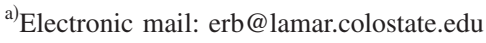

other. Dissociation dynamics of $\left(\mathrm{SO}_{2}\right)_{n}$ clusters have been explored on the femtosecond time scale. ${ }^{5}$ The lifetime of the $E$ electronic state of $\left(\mathrm{SO}_{2}\right)_{n}$ increases as cluster size $n$ increases. This has been explained as due to a "cage effect" associated with the cluster. $\left(\mathrm{SO}_{2}\right)_{n-1} \mathrm{SO}^{+}$and $\left(\mathrm{SO}_{2}\right)_{n-1} \mathrm{~S}^{+}$are identified as the main products for femtosecond multiphoton ionization. To explore the neutral cluster distribution and the dynamics of cluster formation and fragmentation, single photon ionization near the ionization threshold is the best approach, but $\mathrm{SO}_{2}$ clusters have a high ionization energy; even $118 \mathrm{~nm}$ (10.5 eV single photon energy) laser radiation is not sufficient to ionize $\mathrm{SO}_{2}$ clusters.

The reaction of $\mathrm{SO}_{2}$ solvated by water is a part of the acid rain formation process and thus clusters of $\mathrm{H}_{2} \mathrm{O} / \mathrm{SO}_{2}$ are also an object of some scrutiny. Theoretical studies ${ }^{6}$ indicate that a high barrier exists for the reaction $\mathrm{SO}_{2} \cdot \mathrm{H}_{2} \mathrm{O}$ $\rightarrow \mathrm{H}_{2} \mathrm{SO}_{3}$. Li and $\mathrm{Mckee}^{7}$ find that the decomposition of $\mathrm{H}_{2} \mathrm{SO}_{3}$ is catalyzed by the presence of additional water molecules, which lower the barrier for the reaction $\mathrm{H}_{2} \mathrm{SO}_{3}$ $\rightarrow \mathrm{H}_{2} \mathrm{O}+\mathrm{SO}_{2}$. Microwave spectroscopy of $\mathrm{H}_{2} \mathrm{O} \cdot \mathrm{SO}_{2}$ shows the cluster structure as non-hydrogen-bonded and the water and sulfur dioxide planes are tilted approximately $45^{\circ}$ from a parallel orientation, with the $\mathrm{O}$ atom of $\mathrm{H}_{2} \mathrm{O}$ lying above the 
$\mathrm{S}$ atom of $\mathrm{SO}_{2}{ }^{8}$ The vibrational frequencies of each molecule in the mixed dimer are similar to those of the individual molecules. ${ }^{9}$ Theoretical calculations indicate that the interaction in the $\mathrm{SO}_{2} \cdot \mathrm{H}_{2} \mathrm{O}$ complex is not dominated by hydrogen bonding, as the two molecular planes are stacked and somewhat parallel. ${ }^{10,11}$

Mixed sulfur dioxide/water clusters have also been studied with multiphoton femtosecond ionization reflectron time of flight mass spectroscopy (TOFMS). ${ }^{12,13}$ The measured times for dissociation are independent of cluster size, indicating that the ions formed are all at the cluster surface rather than "solvated" by the other, neutral members of the cluster. $\mathrm{SO}_{2}$ molecules are thus more likely to be weakly absorbed rather than solvated in a low water environment. All detected mixed clusters under femtosecond multiphoton ionization are protonated ions, $\left(\mathrm{SO}_{2}\right)_{n}\left(\mathrm{H}_{2} \mathrm{O}\right)_{m} \mathrm{H}^{+}(m \geqslant 0)$. Based on the thermodynamic analysis of Ref. 12 for the mixed dimer $\mathrm{SO}_{2} \cdot \mathrm{H}_{2} \mathrm{O}$, the ion-molecule reaction for the proton transfer from $\mathrm{H}_{2} \mathrm{O}$ to $\mathrm{SO}_{2}$ is favorable following ionization. Nonetheless, theoretical calculations indicate that the stable gas phase complex $\mathrm{SO}_{2} \cdot \mathrm{H}_{2} \mathrm{O}$ should exist with a strong bond $(\sim 3.5 \mathrm{kcal} / \mathrm{mol})::^{10}$ this bond is not dominated by hydrogen bonding. Thus, the dimer might have a high barrier to proton transfer. Compared to hydrogen bonded water clusters, more energy should be required to overcome the barrier to proton transfer for $\mathrm{SO}_{2} \cdot \mathrm{H}_{2} \mathrm{O}$. In the present study we observe both the $\left(\mathrm{SO}_{2}\right)_{n}\left(\mathrm{H}_{2} \mathrm{O}\right)^{+}$and the protonated $\mathrm{SO}_{2}\left(\mathrm{H}_{2} \mathrm{O}\right)_{n} \mathrm{H}^{+}$series of cluster ions in the TOFMS following ionization by single photon, $26.5 \mathrm{eV}$ soft x-ray laser light. Mechanisms for mixed cluster formation and ionization will be discussed in this report.

Previously we have shown that $26.5 \mathrm{eV}$ single photon ionization of van der Waals clusters [e.g., $\left(\mathrm{H}_{2} \mathrm{O}\right)_{n}$, $\left.\left(\mathrm{CH}_{3} \mathrm{OH}\right)_{n}, \quad\left(\mathrm{NH}_{3}\right)_{n}\right]$ is virtually free of cluster fragmentation. ${ }^{14}$ The photoelectron is suggested to carry away with it most, if not all, of the energy above the vertical ionization energy (VIE) of the molecule or cluster. In the present study, distributions of neutral $\left(\mathrm{SO}_{2}\right)_{n}$ and mixed $\left(\mathrm{SO}_{2}\right)_{n}\left(\mathrm{H}_{2} \mathrm{O}\right)_{m}$ clusters are determined, and the metastable dissociation rate constants of $\left(\mathrm{SO}_{2}\right)_{n}^{+}$clusters are measured. We document that, during the single photon ionization process, the clusters suffer only a small fragmentation compared with multiphoton femtosecond ionization. The photodissociation fraction for $\left(\mathrm{SO}_{2}\right)_{n}$ clusters at $26.5 \mathrm{eV}$ photon energy decreases with increasing cluster size. Unprotonated cluster ions $\left(\mathrm{SO}_{2}\right)_{n}\left(\mathrm{H}_{2} \mathrm{O}\right)^{+}$and protonated $\left(\mathrm{SO}_{2}\right)\left(\mathrm{H}_{2} \mathrm{O}\right)_{n} \mathrm{H}^{+}$cluster ions are observed at different experimental conditions. Mechanisms for such phenomena are discussed.

\section{EXPERIMENTAL PROCEDURES}

The experimental approach for these studies has been described in detail in previous publications from our laboratory, ${ }^{14}$ and only a general outline of the experimental scheme will be given here. A tabletop soft x-ray laser ( $26.5 \mathrm{eV} /$ photon, $46.9 \mathrm{~nm}$ ) is used as the ionization source for accessing the neutral clusters of interest. The laser emits pulses of about $1 \mathrm{~ns}$ duration with an energy of about $10 \mu \mathrm{J} / \mathrm{pulse}$ at a repetition rate of up to $12 \mathrm{~Hz}{ }^{15}$ A time of

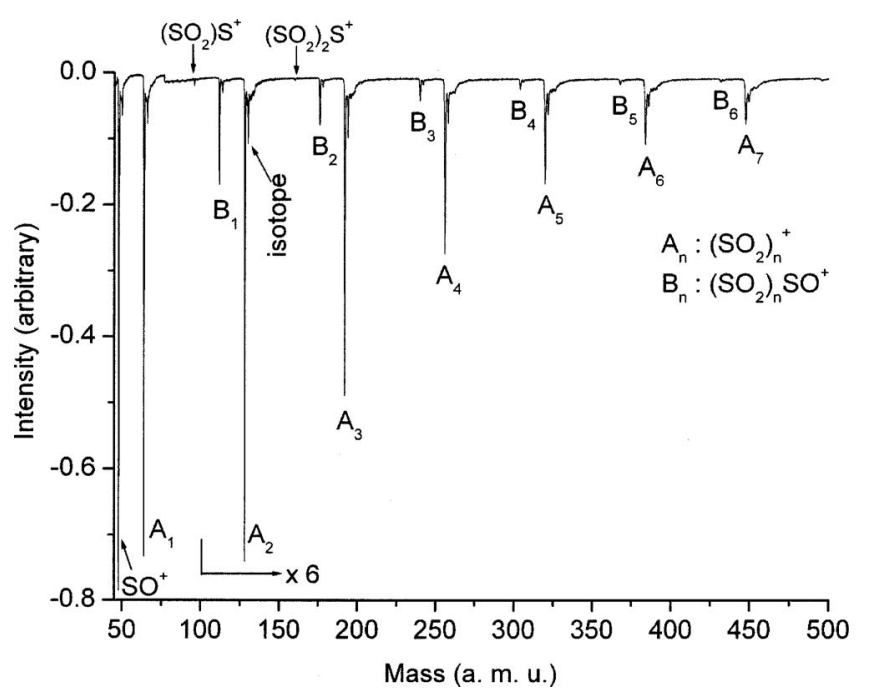

FIG. 1. A linear TOF mass spectrum of the $\mathrm{SO}_{2}$ clusters ionized by a $26.5 \mathrm{eV}$ soft $\mathrm{x}$-ray laser. The $\mathrm{SO}_{2}$ clusters are generated by expansion of a mixed gas of $20 \% \mathrm{SO}_{2} / 80 \% \mathrm{He}$ at 80 psi.

flight mass spectrometer (linear/reflectron) is employed to analyze cluster mass and fragmentation kinetics. A pair of mirrors placed in a $Z$-fold configuration just before the ionization region of the TOFMS provides alignment capability and focus for the $\mathrm{x}$-ray laser beam with respect to the cluster beam. The $Z$-fold mirror system has a total transmissivity of about $10 \%$. Since $26.5 \mathrm{eV}$ photons from the soft $\mathrm{x}$-ray laser are able to ionize the He carrier gas in the beam, the microchannel plate (MCP) detector voltage is gated to reduce the gain of the MCP when $\mathrm{He}^{+}$arrives at the detector in order to prevent detector circuit overload and saturation.

Pure neutral clusters $\left(\mathrm{SO}_{2}\right)_{n}$ are generated in a supersonic expansion of $20 \% \mathrm{SO}_{2} / 80 \% \mathrm{He}$ mixed gases from a pulsed nozzle (200 $\mu \mathrm{m}$ diameter) at 80 psi backing pressure. A mixture of $\mathrm{SO}_{2}$ and $\mathrm{H}_{2} \mathrm{O}$ gases is obtained by flowing $5 \%$ or $20 \% \mathrm{SO}_{2} / \mathrm{He}$ at a pressure of 30 or $80 \mathrm{psi}$ through a reservoir containing liquid distilled water at room temperature. Mixed $\left(\mathrm{SO}_{2}\right)_{n}\left(\mathrm{H}_{2} \mathrm{O}\right)_{m}$ clusters are generated in the supersonic expansion into the vacuum system. $\mathrm{SO}_{2}$ gas used in the experiment is $99.8 \%$ pure (Aldrich, Co.), and the $\mathrm{He}$ gas (99.9\%) is purchased from General Air Co. The expanded supersonic molecular beam is collimated by a conical skimmer with a $2.0 \mathrm{~mm}$ diameter hole. The skimmer is located approximately $2 \mathrm{~cm}$ downstream from the nozzle. Chamber pressure in the field-free and detector regions of the TOFMS is maintained at $2 \times 10^{-6}$ torr during the experiment. Experiments are conducted to ensure that collision induced dissociation of cluster ions is negligible. Pressure in the skimmed supersonic beam is low enough in the ionization region (ca. $10^{-5}$ torr) that collision induced ionization of the clusters is not a likely occurrence.

\section{EXPERIMENTAL RESULTS}

\section{A. Distribution of $\mathrm{SO}_{2}$ clusters ionized by $26.5 \mathrm{eV}$, soft $x$-ray laser radiation ionization}

Figure 1 displays a linear TOFM spectrum of neutral $\mathrm{SO}_{2}$ clusters ionized by $26.5 \mathrm{eV}$, soft x-ray laser radiation. 


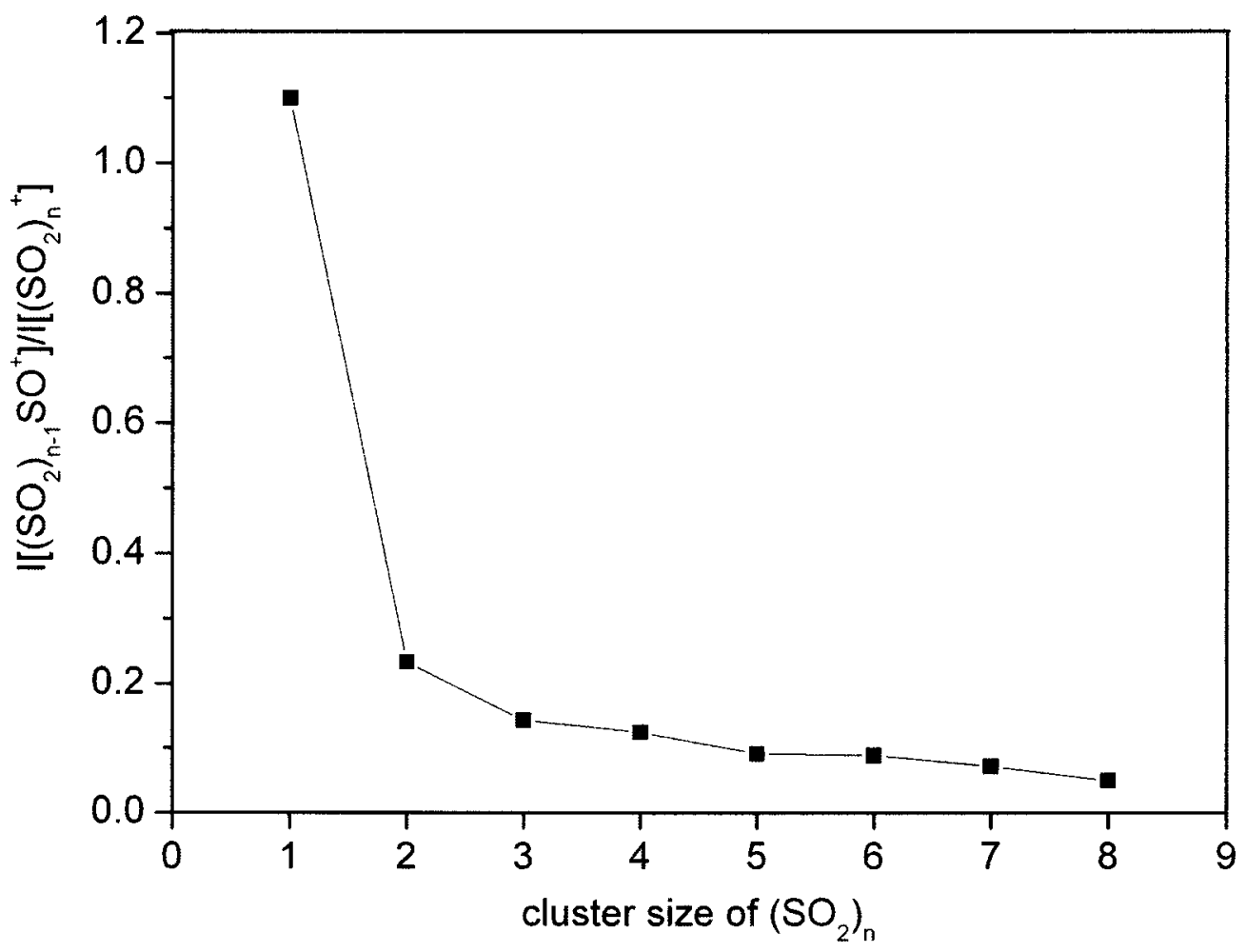

FIG. 2. Dissociation fraction of $\left(\mathrm{SO}_{2}\right)_{n}$ clusters at the $26.5 \mathrm{eV}$ photon energy.

The mass spectrum reflects the size distribution of cluster ions generated in the acceleration/ionization region of the TOFMS, less than $1 \mu$ s after ionization. Two series of cluster ions are identified in the spectrum. The peaks labeled $A_{n}$ represent the cluster series $\left(\mathrm{SO}_{2}\right)_{n}^{+}$, and the peaks labeled $B_{n}$ represent the cluster series $\left(\mathrm{SO}_{2}\right)_{n} \mathrm{SO}^{+}$. The distribution of $\left(\mathrm{SO}_{2}\right)_{n}^{+}(2 \leqslant n \leqslant 25)$ clusters observed in the linear TOFMS decreases roughly exponentially with increasing cluster size $n$. We will argue in Sec. IV that both $\left(\mathrm{SO}_{2}\right)_{n-1} \mathrm{SO}^{+}$and $\left(\mathrm{SO}_{2}\right)_{n}^{+}$cluster ions are directly generated from the same neutral parent $\left(\mathrm{SO}_{2}\right)_{n}$ in the molecular beam by the following reactions:

$$
\begin{aligned}
& \left(\mathrm{SO}_{2}\right)_{n}+h \nu \rightarrow\left(\mathrm{SO}_{2}\right)_{n}^{+}+e^{-} \\
& \left(\mathrm{SO}_{2}\right)_{n}+h \nu \rightarrow\left\{\left(\mathrm{SO}_{2}\right)_{n}^{*}\right\}^{+}+e^{-} \rightarrow\left(\mathrm{SO}_{2}\right)_{n-1} \mathrm{SO}^{+}+\mathrm{O}+e^{-}
\end{aligned}
$$

The $\left(\mathrm{SO}_{2}\right)_{n}^{+}$cluster series $A_{n}$ is the predominant one in the linear TOFMS following single photon ionization of neutral clusters $\left(\mathrm{SO}_{2}\right)_{n}$ by $26.5 \mathrm{eV}$ photons. The distribution in Fig. 1 is different from that obtained by femtosecond multiphoton ionization, which is dominated by the ionization dissociation products $\left(\mathrm{SO}_{2}\right)_{n-1} \mathrm{SO}^{+}$. The dissociation fraction of neutral $\left(\mathrm{SO}_{2}\right)_{n}$ clusters at $26.5 \mathrm{eV}$ ionization is shown in Fig. 2. The intensity ratios $I\left[\left(\mathrm{SO}_{2}\right)_{n-1} \mathrm{SO}^{+}\right] / I\left[\left(\mathrm{SO}_{2}\right)_{n}^{+}\right]$are between 0.24 and 0.04 for cluster sizes $2 \leqslant n \leqslant 8$. These dissociation fractions decrease with increasing cluster size. The $\mathrm{SO}^{+}$ion is assigned as the fragment photodissociation product of $\mathrm{SO}_{2}$ monomer: the $I\left[\mathrm{SO}^{+}\right] / I\left[\mathrm{SO}_{2}^{+}\right]$is about 1.1. A number of minor fragmented species can also be identified: $\mathrm{S}^{+}$generated from $\mathrm{SO}_{2}$ by loss of $\mathrm{O}_{2}$ and $\left(\mathrm{SO}_{2}\right) \mathrm{S}^{+}$and $\left(\mathrm{SO}_{2}\right)_{2} \mathrm{~S}^{+}$generated by the loss of $\mathrm{O}_{2}$ from $\left(\mathrm{SO}_{2}\right)_{2}$ and $\left(\mathrm{SO}_{2}\right)_{3}$, respectively. Al- though the masses of ${ }^{16} \mathrm{O}_{2}$ and ${ }^{35} \mathrm{~S}$ overlap, the species $\mathrm{S}^{+}$ can be identified from the background ${ }^{16} \mathrm{O}_{2}^{+}$signal by the presence of ${ }^{34} \mathrm{~S}^{+}$.

\section{B. Metastable dissociation rate constants for $\left(\mathrm{SO}_{2}\right)_{n}^{+}$ clusters}

The spectrum of Fig. 3 is obtained in the reflectron mode of the TOFMS. It indicates the population distribution of cluster ions formed in the first field-free region within the time region of 1-90 $\mu$ s. If the fragmentation were to happen in the acceleration region, the TOF spectrum would indicate this with mass peaks broadly dispersed in time. Since the

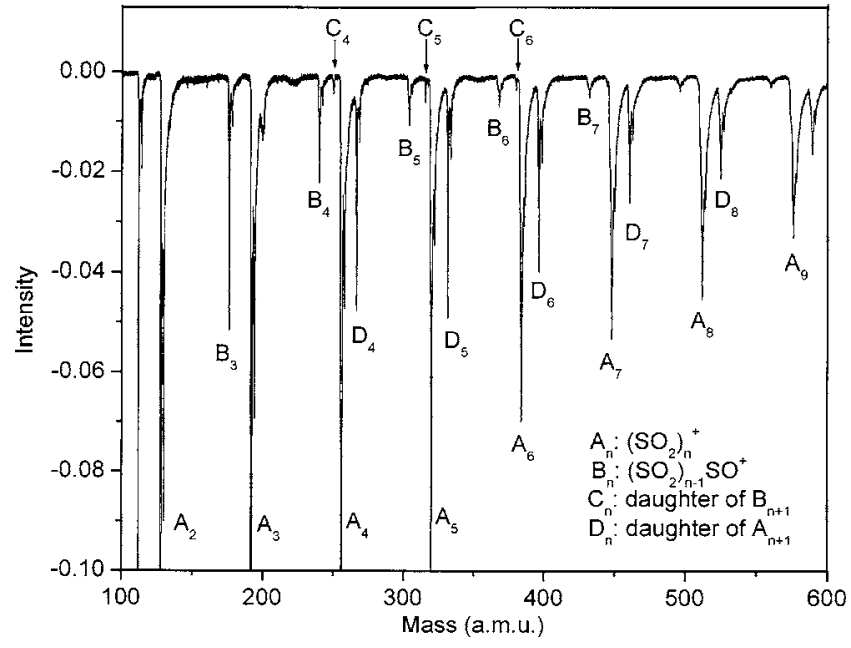

FIG. 3. A high resolution reflectron TOF mass spectrum of the $\mathrm{SO}_{2}$ clusters. The metastable dissociation of $\left(\mathrm{SO}_{2}\right)_{n}^{+}$and $\left(\mathrm{SO}_{2}\right)_{n} \mathrm{SO}^{+}$cluster ions in the field-free region is observed. 


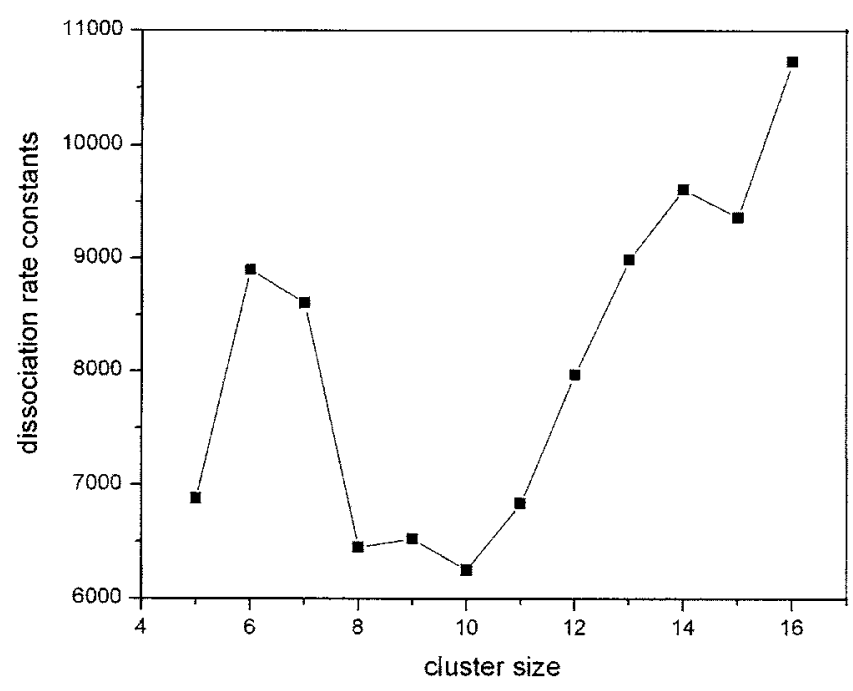

FIG. 4. A plot of the metastable dissociation rate constants for $\left(\mathrm{SO}_{2}\right)_{n}^{+}$cluster ions as a function of the cluster size $n$.

fragmentation happens in the field-free region the parent and daughter signals are separated by reflectron mass spectrometer ${ }^{16}$ with good temporal resolution. Compared to the spectrum displayed in Fig. 1, two new series of cluster ions can be identified. The peaks marked $D_{n}$ are the daughter cluster ions of the parent cluster ions $\left(\mathrm{SO}_{2}\right)_{n+1}^{+}\left(A_{n+1}\right)$, and the peaks marked $C_{n}$ are the daughter cluster ions of the parent cluster ions $\left(\mathrm{SO}_{2}\right)_{n+1} \mathrm{SO}^{+}\left(B_{n+1}\right)$. The daughters are produced from their parents by metastable dissociation reactions in the first field-free TOFMS drift tube section. In the present experiment the loss of only one $\mathrm{SO}_{2}$ molecule by this mechanism is observed. The unimolecular dissociation rate constant of $\left(\mathrm{SO}_{2}\right)_{n}^{+}$cluster ions can be calculated based on the following equation: ${ }^{17}$

$$
k=-\left(\frac{1}{t}\right) \ln \left[1-\frac{\left(I_{D}\right)}{\left(I_{D}+I_{P}\right)}\right],
$$

in which $I_{D}$ and $I_{P}$ are the intensities of the dissociated daughter ions and the undissociated parent ions, respectively. $t$ is the flight time of the parent ion in the first field-free region of the reflectron TOFMS. For the present apparatus this time is about $60 \%$ of the total flight time. As shown in Fig. 4, the metastable rate constants for $\left(\mathrm{SO}_{2}\right)_{n}^{+}$losing $\mathrm{SO}_{2}$ are in the range of $(0.6-1.1) \times 10^{4} \mathrm{~s}^{-1}$ for cluster sizes 5 $\leqslant n \leqslant 16$. Clusters $\left(\mathrm{SO}_{2}\right)_{6}^{+}$and $\left(\mathrm{SO}_{2}\right)_{7}^{+}$show fast dissociation rates relative to their neighbors.

\section{Mixed sulfur dioxide-water clusters}

Mixed $\left(\mathrm{SO}_{2}\right)_{n}\left(\mathrm{H}_{2} \mathrm{O}\right)_{m}$ clusters are generated by expanding a three component $\mathrm{SO}_{2} / \mathrm{H}_{2} \mathrm{O} / \mathrm{He}$ gas into the vacuum chamber at room temperature. We have employed two conditions for the generation of $\left(\mathrm{SO}_{2}\right)_{n}\left(\mathrm{H}_{2} \mathrm{O}\right)_{m}$ clusters: (1) $5 \%$ $\mathrm{SO}_{2} / \mathrm{He}$ mixed with water vapor at $T \sim 300 \mathrm{~K}$ and expanded at 30 psi backing pressure and (2). $20 \% \mathrm{SO}_{2} / \mathrm{He}$ mixed with water vapor at $T \sim 300 \mathrm{~K}$ and expanded at 80 psi backing pressure. Figure 5 presents a mass spectrum of mixed $\left(\mathrm{SO}_{2}\right)_{n}\left(\mathrm{H}_{2} \mathrm{O}\right)_{m}$ clusters formed at low concentration of $\mathrm{SO}_{2}$ and low backing pressure [condition (1)]. The series of protonated cluster ions $\left(\mathrm{H}_{2} \mathrm{O}\right)_{n} \mathrm{H}^{+}(n=1, \ldots, 20)$ dominates the

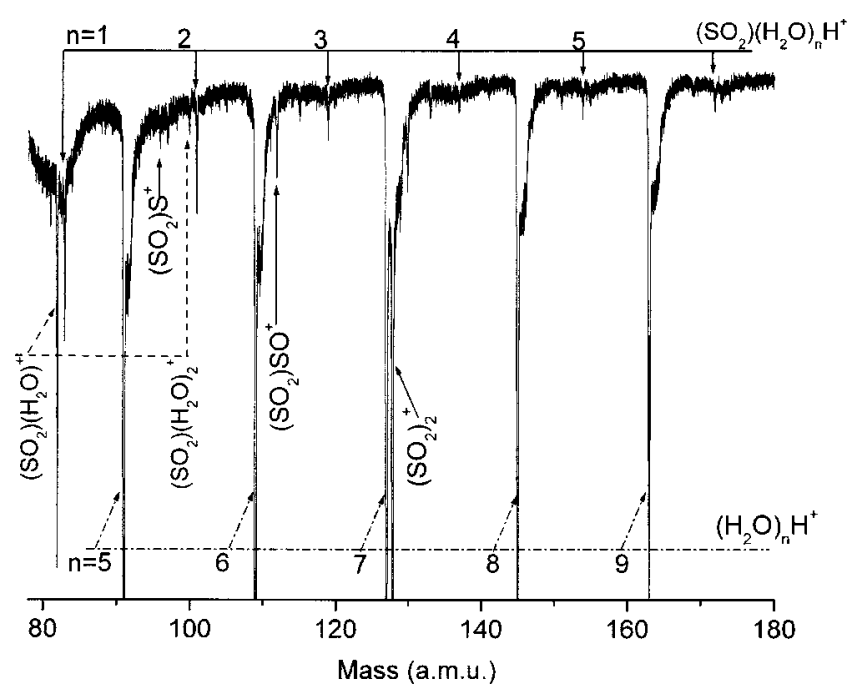

FIG. 5. A high resolution spectrum of mixed $\mathrm{SO}_{2}-\mathrm{H}_{2} \mathrm{O}$ clusters generated by expansion of the mixed gas $5 \% \mathrm{SO}_{2} /$ water vapor/He at 30 psi backing pressure. The protonated water cluster ions $\left(\mathrm{H}_{2} \mathrm{O}\right)_{n} \mathrm{H}^{+}$dominate the mass spectrum. The signal intensity of the mixed cluster ions $\left(\mathrm{SO}_{2}\right)\left(\mathrm{H}_{2} \mathrm{O}\right)_{n} \mathrm{H}^{+}$is about $2 \%$ of the intensity of $\left(\mathrm{H}_{2} \mathrm{O}\right)_{n} \mathrm{H}^{+}$at $n=5,6$.

mass spectrum in this experiment. The $\left(\mathrm{SO}_{2}\right)_{n}^{+}$cluster ions are not observed except for the $\left(\mathrm{SO}_{2}\right)_{2}^{+}$dimer because of the lower concentration of $\mathrm{SO}_{2}$ and low backing pressure. The protonated mixed cluster ions $\left(\mathrm{SO}_{2}\right)\left(\mathrm{H}_{2} \mathrm{O}\right)_{n} \mathrm{H}^{+}$appear in the mass spectrum of Fig. 5 but at a very low intensity. They are generated from the neutral mixed clusters $\left(\mathrm{SO}_{2}\right)\left(\mathrm{H}_{2} \mathrm{O}\right)_{n+1}$ by a proton transfer reaction following ionization:

$$
\begin{aligned}
\left(\mathrm{SO}_{2}\right)\left(\mathrm{H}_{2} \mathrm{O}\right)_{n+1} h \nu & \rightarrow\left\{\left(\mathrm{SO}_{2}\right)\left(\mathrm{H}_{2} \mathrm{O}\right)_{n+1}\right\}^{+}+e^{-} \\
& \rightarrow\left(\mathrm{SO}_{2}\right)\left(\mathrm{H}_{2} \mathrm{O}\right)_{n} \mathrm{H}^{+}+\mathrm{OH}+e^{-}
\end{aligned}
$$

Signal intensities of the mixed clusters $\left(\mathrm{SO}_{2}\right)\left(\mathrm{H}_{2} \mathrm{O}\right)_{n} \mathrm{H}^{+}$are about $2 \%$ of the intensity of $\left(\mathrm{H}_{2} \mathrm{O}\right)_{n} \mathrm{H}^{+}$ions at $n=5,6$. Mixed sulfur dioxide-water clusters containing more than one $\mathrm{SO}_{2}$ molecule are not detected. Note that at mass 82 the $\left(\mathrm{SO}_{2}\right)$ $\times\left(\mathrm{H}_{2} \mathrm{O}\right)^{+}$signal is detected. This latter cluster can be directly generated from ionization of the neutral mixed dimer $\left(\mathrm{SO}_{2}\right)$ $\times\left(\mathrm{H}_{2} \mathrm{O}\right) / \mathrm{H}_{2} \mathrm{SO}_{3}$. No obvious $\mathrm{HSO}_{2}^{+}$signal is observed. We will discuss the generation of mixed $\left(\mathrm{SO}_{2}\right)\left(\mathrm{H}_{2} \mathrm{O}\right)$ clusters in more detail in Sec. IV below.

Figure 6 shows a comparison between metastable dissociation of protonated water clusters generated in a pure water expansion (80 psi He passed over $T \sim 300 \mathrm{~K}$ liquid water), spectrum A, and metastable dissociation of water clusters generated in a mixed sulfur dioxide-water expansion, spectrum B. The peaks labeled $P_{n}$ in this figure are parent cluster ions $\left(\mathrm{H}_{2} \mathrm{O}\right)_{n} \mathrm{H}^{+}$, and those labeled as $D_{n}$ are the daughter ions produced by loss of one $\mathrm{H}_{2} \mathrm{O}$ from its parent ion $P_{n+1}$ due to metastable fragmentation in the drift tube of the reflectron TOFMS. For both systems, the signal intensities of daughter and parent ions switch dominance at ca. $n \sim 14 / 15$. This means that the protonated water cluster ions generated from the two different samples have the same metastable dissociation rate constant in the field-free region.

With the concentration of $\mathrm{SO}_{2}$ in the backing gas increased to $20 \%$ and the backing expansion pressure increased to 80 psi [condition (2)], $\left(\mathrm{SO}_{2}\right)_{n}^{+}$cluster ions dominate the 


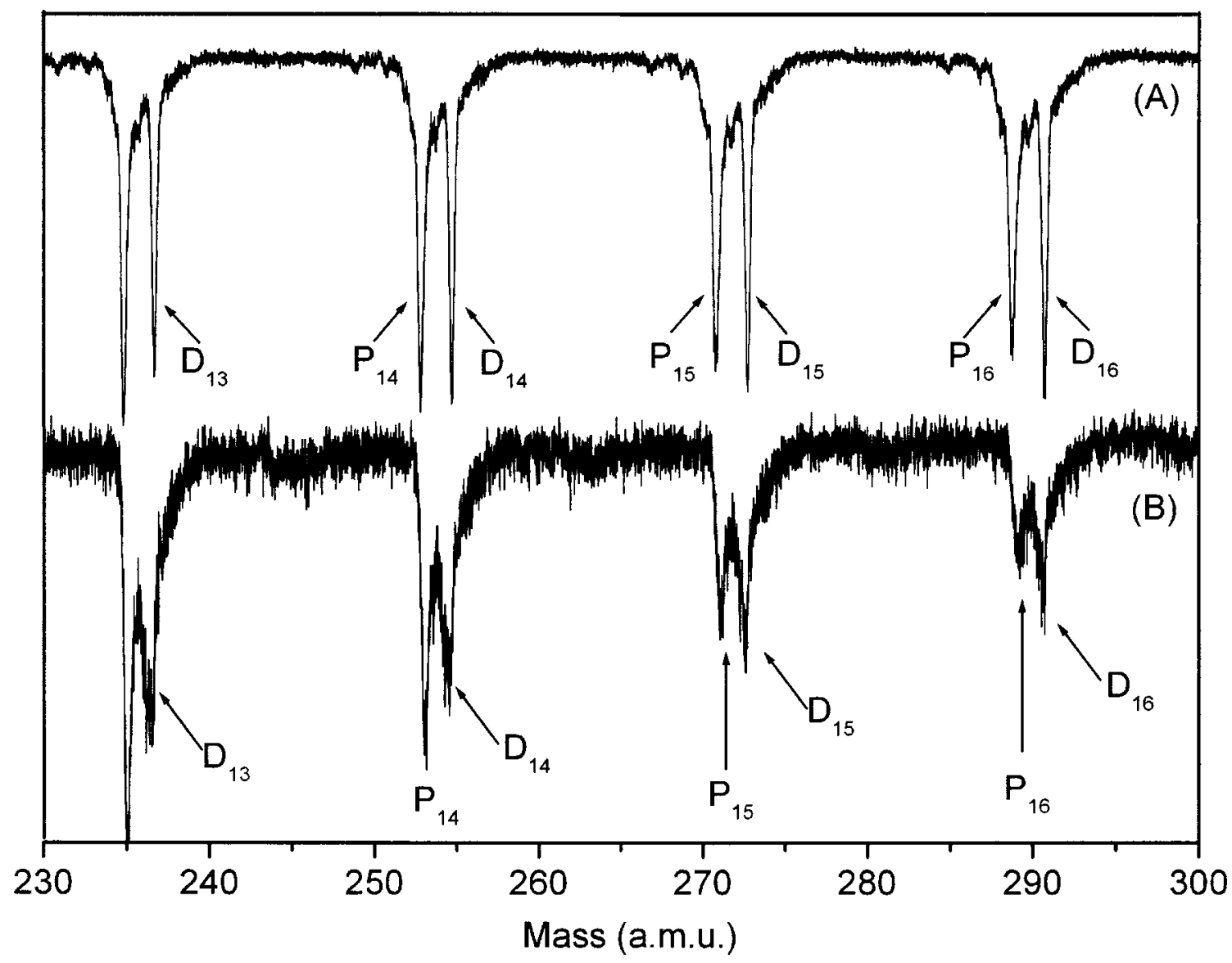

FIG. 6. A comparison of metastable dissociation of protonated water cluster ions formed in a pure water $/ \mathrm{He}$ expansion $($ curve $\mathrm{A})$ and a mixed $\mathrm{SO} \mathrm{O}_{2} / \mathrm{H}_{2} \mathrm{O} / \mathrm{He}$ expansion (curve B). The peaks labeled as $P_{n}$ are the parent cluster ions $\left(\mathrm{H}_{2} \mathrm{O}\right)_{n} \mathrm{H}^{+}$, and the peaks marked as $D_{n}$ are the daughter ions generated by the loss of one $\mathrm{H}_{2} \mathrm{O}$ from its parent ions $P_{n+1}$ in the field-free region of the reflectron TOFMS. For both two systems, the signal intensities of daughter and parent ions switch at $n \sim 14 / 15$.

spectrum and the $\left(\mathrm{H}_{2} \mathrm{O}\right)_{n} \mathrm{H}^{+}$ions are not detected as shown in Fig. 7. All of the mixed cluster ions that are observed in this spectrum are unprotonated $\left(\mathrm{SO}_{2}\right)_{n}\left(\mathrm{H}_{2} \mathrm{O}\right)^{+}(1 \leqslant n \leqslant 5)$. The protonated mixed cluster ions $\left(\mathrm{SO}_{2}\right)\left(\mathrm{H}_{2} \mathrm{O}\right)_{n} \mathrm{H}^{+}$formed

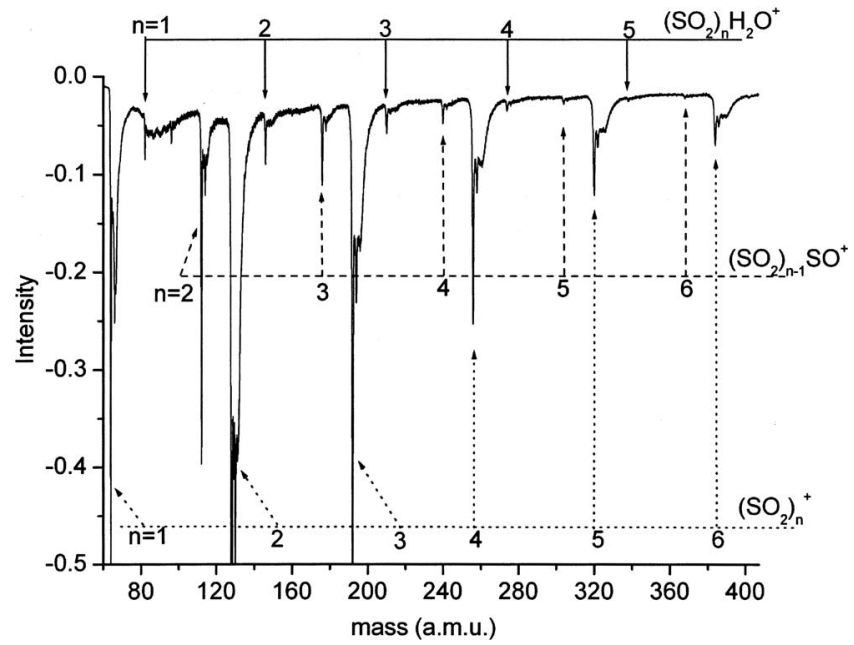

FIG. 7. A high resolution spectrum of mixed $\mathrm{SO}_{2}-\mathrm{H}_{2} \mathrm{O}$ clusters generated by expansion of the mixed gas $20 \% \mathrm{SO}_{2} /$ water vapor/He at 80 psi backing pressure. The cluster ions $\left(\mathrm{SO}_{2}\right)_{n}^{+}$dominate the mass spectrum. Signal intensity of cluster ions $\left(\mathrm{SO}_{2}\right)_{n}\left(\mathrm{H}_{2} \mathrm{O}\right)^{+}$are about $5 \%$ of the intensity of the cluster ions $\left(\mathrm{SO}_{2}\right)_{n}^{+}$at $n=2,3,4$. under condition (1) are not observed. Signal intensities of cluster ions $\left(\mathrm{SO}_{2}\right)_{n}\left(\mathrm{H}_{2} \mathrm{O}\right)^{+}$are about $5 \%$ of the intensities of the $\left(\mathrm{SO}_{2}\right)_{n}^{+}$cluster ions, $n=2,3,4$.

\section{DISCUSSION}

\section{A. Distribution of $\left(\mathrm{SO}_{2}\right)_{n}$ clusters}

Single photon, $26.5 \mathrm{eV}$ ionization of water, methanol, and ammonia clusters yields virtually no fragmentation of those species associated with the ionization, per se. ${ }^{14} \mathrm{Al}-$ though the $26.5 \mathrm{eV}$ photon energy is initially absorbed by the neutral cluster, almost all the photon energy above the VIE of the cluster is removed by the ejected electron. The energy used by the cluster for metastable dissociation is either related to the difference between the VIE and (adiabatic) AIE of the cluster or is derived from the heat of the proton transfer reaction. Thus, distributions of hydrogen bonded (or proton transfer) clusters observed in those experiments are in good agreement with near threshold ionization experiments, such as single photon ionization by VUV resonance lamps $(9.75-11.85 \mathrm{eV})$ and $10.5 \mathrm{eV}$ VUV lasers. ${ }^{18}$ In these experiments, the VIE is always greater than the energy required to drive a proton transfer reaction, and therefore protonated products are always observed. This process cannot be avoided, even when using threshold ionization methods. 
Sulfur dioxide clusters are bound by van der Waals interactions (dispersion) and are more weakly bound than hydrogen bonded clusters such as water and methanol and even non-hydrogen-bonded clusters such as ammonia. As shown in Fig. 1 the distribution of $\left(\mathrm{SO}_{2}\right)_{n}^{+}$clusters decreases roughly exponentially with increasing cluster size. $\left(\mathrm{SO}_{2}\right)_{n}^{+}$clusters dominate the mass spectrum of sulfur dioxide clusters and $\left(\mathrm{SO}_{2}\right)_{n-1} \mathrm{SO}^{+}$cluster ions become very weak at $n \sim 7$. Multiphoton ionization of $\left(\mathrm{SO}_{2}\right)_{n}$ by femtosecond laser excitation shows much more extensive fragmentation, with $\left(\mathrm{SO}_{2}\right)_{n-1} \mathrm{SO}^{+}$features being more intense than parent $\left(\mathrm{SO}_{2}\right)_{n}^{+}$ features. ${ }^{19-21}$ One advantage of femtosecond versus nanosecond multiphoton ionization is that up pumping to the ion state typically precludes dissociation reactions for the neutral cluster during the ultrafast ionization process. Apparently, single photon, even $26.5 \mathrm{eV}$, ionization imparts much less final energy "excess energy" over that required for vertical ionization. Most $\left(\mathrm{SO}_{2}\right)_{n}$ clusters are pumped to the ground state of the ion, and one observes that the $\left(\mathrm{SO}_{2}\right)_{n}^{+}$signal is dominant in the mass spectrum. In this case the energy required to drive the metastable reaction comes from the energy difference between the vertical and adiabatic energy levels. Very few $\left(\mathrm{SO}_{2}\right)_{n}$ neutral clusters are excited to electronically excited states of the ion. ${ }^{3,5}$ The few that are excited, $\left[\left(\mathrm{SO}_{2}\right)_{n}^{+}\right]^{*}$, have sufficient excess energy above the VIE to facilitate the reaction $\left(\mathrm{SO}_{2}\right)_{n}^{+} \rightarrow\left(\mathrm{SO}_{2}\right)_{n-1} \mathrm{SO}^{+}+\mathrm{O}$; the ratios $I\left[\mathrm{SO}_{2} \mathrm{SO}^{+}\right] / I\left[\left(\mathrm{SO}_{2}\right)_{2}^{+}\right]$(Fig. 2) depend on cluster size and decrease with increasing cluster size. In our previous $\left(\mathrm{H}_{2} \mathrm{O}\right)_{n}$ and $\left(\mathrm{CH}_{3} \mathrm{OH}\right)_{n}$ experiments, ${ }^{14}$ the dissociation reactions of the monomer are detected, such as, $\mathrm{H}_{2} \mathrm{O} \rightarrow \mathrm{OH}^{+}+H$ and $\mathrm{CH}_{3} \mathrm{OH} \rightarrow \mathrm{CH}_{3} \mathrm{O}^{+}+\mathrm{H}$; however, such dissociation does not occur for water or methanol clusters. For example, $\left(\mathrm{H}_{2} \mathrm{O}\right)_{n} \mathrm{OH}^{+}$and $\left(\mathrm{CH}_{3} \mathrm{OH}\right)_{n} \mathrm{CH}_{3} \mathrm{O}^{+}$ion signals are not observed in the mass spectra. In the case of $\left(\mathrm{NH}_{3}\right)_{n}$, molecular dissociation is observed for the dimer $\left(\mathrm{NH}_{3}\right)_{2}$ only, which loses up to five $\mathrm{H}$ atoms. The different behaviors of these clusters depend on specific characteristics of the cluster, such as photoabsorption cross section of the excited state of the cluster ion, which is sensitive to the cluster size and molecular properties.

We have measured the unimolecular (metastable) dissociation rate constants for reactions involving loss of one neutral molecule. These are $(0.6-2.7) \times 10^{4} \mathrm{~s}^{-1}$ for water $(5$ $\leqslant n \leqslant 18),(0.36-0.6) \times 10^{4} \mathrm{~s}^{-1}$ for methanol $(5 \leqslant n \leqslant 10)$, and $(0.8-2.0) \times 10^{4} \mathrm{~s}^{-1}$ for ammonia $(5 \leqslant n \leqslant 18)$. In the present experiment, unimolecular dissociation rate constants for loss of one $\mathrm{SO}_{2}$ molecule from $\left(\mathrm{SO}_{2}\right)_{n}^{+}$are $(0.6-1.5)$ $\times 10^{4} \mathrm{~s}^{-1}$ for cluster sizes $5 \leqslant n \leqslant 16$. Note that even though those clusters have a wide range of binding energies and structures, these rate constants are similar. One can extract two conclusions from these similar cluster kinetics: (1) $\left(\mathrm{SO}_{2}\right)_{n}^{+}$cluster ions do not acquire much excess energy above their VIE in single photon ionization in a similar manner to water, methanol, and ammonia cluster ions; (2) cluster dynamics must be more related to cluster size, excess energy, degrees of freedom, and densities of states than detailed cluster structure and the approximate nature of the limiting potential interaction functions (e.g., dipole-dipole, hydrogen bonding, dispersion, etc.). The situation is actually rather complicated because the hydrogen bonded clusters $\left[\left(\mathrm{H}_{2} \mathrm{O}\right)_{n}\right.$ and $\left.\left(\mathrm{CH}_{3} \mathrm{OH}\right)_{n}\right]$ and donor/acceptor clusters $\left[\left(\mathrm{NH}_{3}\right)_{n}\right]$ employ the excess cluster energy (over IE) to drive the proton transfer reaction with $\Delta \mathrm{H}<0$ and fragment a $\mathrm{OH}, \mathrm{CH}_{3} \mathrm{O}$, or $\mathrm{NH}_{2}$ radical before undergoing metastable fragmentation of a consistent neutral molecule, while $\left(\mathrm{SO}_{2}\right)_{n}$ clusters simply employ the VIE/AIE difference for metastable fragmentation of $\mathrm{SO}_{2}$.

Based on our results, we consider that most neutral sulfur dioxide clusters $\left(\mathrm{SO}_{2}\right)_{n}$ are free of fragmentation directly following single photon ionization by the soft x-ray laser. This claim can be supported by three main observations. First, the peaks observed in the mass spectra are sharp and symmetrical, and thus fragmentation while the cluster is in the high field ionization region $(<1 \mu \mathrm{s})$ does not occur. Second, the loss of only one sulfur dioxide molecule is observed in the field-free region after ionization. The metastable rate constants of the sulfur dioxide cluster ions are similar to those for water, ammonia, and methanol. ${ }^{14}$ In Ref. 14 many arguments are presented that support almost no fragmentation for these clusters. Similar rate constants indicate similar behavior of the clusters as they undergo ionization. Third, we observe unprotonated mixed water-sulfur dioxide clusters. This shows that during ionization, the amount of energy left in the mixed cluster is too small to drive a proton transfer reaction. This will be discussed in more detail in the following sections.

\section{B. Effect of cluster size $n$ on the photodissociation of $\left(\mathrm{SO}_{2}\right)_{n}$ clusters}

One can identify two distinct types of dissociation of the clusters following ionization: (1) metastable dissociation in which slow dissociation involves the breaking of a van der Waals bond between one molecule member of the cluster and the rest of the cluster and (2) intramolecular dissociation of a cluster molecule followed by loss of a neutral atomic or molecular radical (e.g., $\mathrm{O}, \mathrm{OH}, \mathrm{NH}_{2}$, etc.). In the first instance, the dissociation rate constant increases with cluster size (see Figs. 4 and 6). In the second case, the rate constant for intramolecular fragmentation decreases with increasing cluster size (see Fig. 2).

$\mathrm{SO}_{2}$ and $\left(\mathrm{SO}_{2}\right)_{2}$ have been studied at high resolution by photoionization spectroscopy in a molecular beam. ${ }^{3}$ The IE $\left(\mathrm{SO}_{2}\right)=12.35 \mathrm{eV}$ and the appearance energy $(\mathrm{AE})$ for the reaction $\mathrm{SO}_{2}+h \nu \rightarrow \mathrm{SO}^{+}+\mathrm{O}+e^{-}$is $15.953 \mathrm{eV}, 3.6 \mathrm{eV}$ above the ion ground state of $\mathrm{SO}_{2}^{+}$. The $26.5 \mathrm{eV}$ photon can access both of these processes. The IE $\left(\mathrm{SO}_{2}\right)_{2}$ is $11.72 \mathrm{eV}$ and the $\mathrm{AE}$ for $\mathrm{SO}_{2} \mathrm{SO}^{+}$is $15.38 \mathrm{eV}$. At $65 \mathrm{~nm}(19.07 \mathrm{eV})$ excitation, the photoionization dissociation fraction $I\left[\mathrm{SO}_{2} \mathrm{SO}^{+}\right] / I\left[\left(\mathrm{SO}_{2}\right)_{2}^{+}\right] \sim 0.08$ and $I\left[\mathrm{SO}^{+}\right] / I\left[\mathrm{SO}_{2}^{+}\right] \sim 0.56$. This suggests that the ionization energy and dynamics of photodissociation are different in the molecule and dimer. In our $\quad 46.9 \mathrm{~nm} \quad(26.5 \mathrm{eV}) \quad$ excitation experiment $I\left[\mathrm{SO}_{2} \mathrm{SO}^{+}\right] / I\left[\left(\mathrm{SO}_{2}\right)_{2}^{+}\right] \sim 0.23$ and $I\left[\mathrm{SO}^{+}\right] / I\left[\mathrm{SO}_{2}^{+}\right] \sim 1.1$. For larger clusters the dissociation fraction decreases rapidly with increasing $n$ as reported in Fig. 2. Under femtosecond photodissociation and ionization, a sequential increase in lifetime associated with the $\mathrm{SO}_{2}$ neutral $E$ state is found and 
attributed to steric hindrance for the dissociation reaction. ${ }^{5}$ Studies with $\mathrm{CH}_{3} \mathrm{I}$ and $\mathrm{H}_{2} \mathrm{O}$ have referred to a solvent cage effect for these cluster processes. ${ }^{22-24}$

A more general approach to these relaxation and dissociation phenomena in van der Waals clusters is through the concepts of intracluster vibrational redistribution (IVR) of energy and vibration predissociation (VP) ${ }^{25-28}$ In this approach one need not assume or imagine a particular structure for the cluster (e.g., ion in its center, ion on the surface, etc.). The two processes IVR and VP are considered as serial phenomena in which energy flows from the initial site of excitation following ionization to cluster modes and then the cluster can dissociate. IVR is enhanced by larger clusters (more density of states), while VP is retarded by a large density of states. For the case at hand, the $26.5 \mathrm{eV}$ photon ionizes a $\mathrm{SO}_{2}$ molecule in the cluster and the excess energy above VIE is removed by the photoelectron for most of the clusters (see Fig. 2). The remaining energy above the IE of the cluster is redistributed to the cluster modes through IVR; this is apparently a small enough amount of energy such that VP is slow $(\sim 1-80 \mu \mathrm{s})$. In small clusters [e.g., $\left(\mathrm{SO}_{2}\right)_{2}$ ] or the $\mathrm{SO}_{2}$ monomer, the excess energy can stay in the excited molecule for hundreds of picoseconds and local bond fragmentation $\left(\mathrm{SO}^{+}, \mathrm{SO}_{2} \mathrm{SO}^{+}\right.$, etc. $)$can occur. In larger clusters, IVR is fast (ca. 1-10 ps) and molecular photodissociation VP would be generated, as observed.

\section{Generation of mixed $\left(\mathrm{SO}_{2}\right)_{n}\left(\mathrm{H}_{2} \mathrm{O}\right)_{m}$ clusters}

The binding energies of van der Waals clusters can vary over a wide range, for example, $0.22 \mathrm{eV}$ for $\left(\mathrm{H}_{2} \mathrm{O}\right)_{2}$ hydrogen bonded dimer ${ }^{29,30}$ to $0.03 \mathrm{eV}$ for the $\left(\mathrm{SO}_{2}\right)_{2}$ dimer. $^{3}$ Thus water clusters are more stable and more easily formed than $\left(\mathrm{SO}_{2}\right)_{n}$ clusters in a molecular beam. For the condition of low concentration of $\mathrm{SO}_{2}\left(5 \% \mathrm{SO}_{2} / \mathrm{He} /\right.$ water vapor $)$ and low backing pressure of the expansion gas mixture, protonated water cluster ions dominate the mass spectrum, and only the $\left(\mathrm{SO}_{2}\right)_{2}^{+}$dimer ion is detected (Fig. 5). The distribution of $\left(\mathrm{H}_{2} \mathrm{O}\right)_{n} \mathrm{H}^{+}$cluster ions generated in this beam condition is the same as that formed for a pure $\mathrm{H}_{2} \mathrm{O} / \mathrm{He}$ expansion. Two possible channels exist for the mixed $\mathrm{SO}_{2} / \mathrm{H}_{2} \mathrm{O}$ system to form $\left(\mathrm{H}_{2} \mathrm{O}\right)_{n} \mathrm{H}^{+}$in the expansion/ionization processes. First, they can be directly generated from the neutral water cluster,

$$
\begin{aligned}
\left(\mathrm{H}_{2} \mathrm{O}\right)_{n}+h \nu & \rightarrow\left\{\left(\mathrm{H}_{2} \mathrm{O}\right)_{m}^{+}\right\}^{*}+e^{-} \\
& \rightarrow\left(\mathrm{H}_{2} \mathrm{O}\right)_{n-1} \mathrm{H}^{+}+e^{-}+\mathrm{OH} .
\end{aligned}
$$

Second, they can be generated from a mixed cluster in a loss of one or more $\mathrm{SO}_{2}$ molecules leading to the formation of protonated water clusters as

$$
\begin{aligned}
\left(\mathrm{SO}_{2}\right)_{m}\left(\mathrm{H}_{2} \mathrm{O}\right)_{n}+h \nu \rightarrow & \left.\left\{\left(\mathrm{SO}_{2}\right)_{m}\right)\left(\mathrm{H}_{2} \mathrm{O}\right)_{n}^{+}\right\}^{*}+e^{-} \\
\rightarrow & \left(\mathrm{H}_{2} \mathrm{O}\right)_{n-1} \mathrm{H}^{+}+\mathrm{OH}+e^{-} \\
& +m \mathrm{SO}_{2}(m \geqslant 1)
\end{aligned}
$$

Femtosecond studies of these clusters suggest that the protonated water cluster ions $\left(\mathrm{H}_{2} \mathrm{O}\right)_{n} \mathrm{H}^{+}$are generated from $\left(\mathrm{SO}_{2}\right)\left(\mathrm{H}_{2} \mathrm{O}\right)_{n}$ neutrals. ${ }^{12,13,21}$ Nonetheless, results presented in the present work (Fig. 6) lead to the conclusion that $\left(\mathrm{H}_{2} \mathrm{O}\right)_{n-1} \mathrm{H}^{+}$arise from $\left(\mathrm{H}_{2} \mathrm{O}\right)_{n}$ neutrals. If $\mathrm{SO}_{2}\left(\mathrm{H}_{2} \mathrm{O}\right)_{n}$ neu- tral clusters were the parent of the $\left(\mathrm{H}_{2} \mathrm{O}\right)_{n-1} \mathrm{H}^{+}$cluster ion, then excess cluster energy in the ionization process would be removed from the ion by loss of $\mathrm{SO}_{2}$ molecules as has been found for the $\left(\mathrm{H}_{2} \mathrm{O}\right)_{n} \mathrm{Ar}_{m}$ system. In this case $\left(\mathrm{H}_{2} \mathrm{O}\right)_{n}^{+}$would be observed and different metastable fragmentation kinetics would be expected in the drift tube region. Neither is observed, and thus one concludes that the $\left(\mathrm{H}_{2} \mathrm{O}\right)_{n-1} \mathrm{H}^{+}$parent ions come from $\left(\mathrm{H}_{2} \mathrm{O}\right)_{n}$ neutrals. In a separate experiment on carbon dioxide-water clusters, the unprotonated cluster ions $\left(\mathrm{H}_{2} \mathrm{O}\right)_{n}^{+}$are observed due to loss of several $\mathrm{CO}_{2}$ molecules from the ionized cluster. ${ }^{31}$ No unprotonated $\left(\mathrm{H}_{2} \mathrm{O}\right)_{n}^{+}$cluster ions are observed for the $\mathrm{SO}_{2} / \mathrm{H}_{2} \mathrm{O}$ system presently under consideration.

Weak signal intensity is also observed for cluster ions $\left(\mathrm{SO}_{2}\right)\left(\mathrm{H}_{2} \mathrm{O}\right)_{n} \mathrm{H}^{+}$as seen in Fig. 5. Mixed $\mathrm{SO}_{2} / \mathrm{H}_{2} \mathrm{O}$ clusters containing more than one $\mathrm{SO}_{2}$ moiety are not observed for the $5 \% \mathrm{SO}_{2} / \mathrm{He}$ low pressure expansion conditions that apply for this figure: $\mathrm{SO}_{2}$ is not easily dissolved in water clusters. At high $\mathrm{SO}_{2}$ concentrations in the beam and high expansion pressures $\left(20 \% \mathrm{SO}_{2} / \mathrm{H}_{2} \mathrm{O} / \mathrm{He}, 80 \mathrm{psi}\right),\left(\mathrm{SO}_{2}\right)_{n}^{+}$is the dominant product (Fig. 7). Signal intensity of the mixed cluster ion $\left(\mathrm{SO}_{2}\right)_{n}\left(\mathrm{H}_{2} \mathrm{O}\right)^{+}$is much weaker than that for the $\left(\mathrm{SO}_{2}\right)_{n}^{+}$cluster ion. The mixed cluster series containing only one $\mathrm{H}_{2} \mathrm{O}$ molecule, $\left(\mathrm{SO}_{2}\right)_{n}\left(\mathrm{H}_{2} \mathrm{O}\right)^{+}$, is weakly observed. Thus $\left(\mathrm{SO}_{2}\right)_{n}$ is not a good solvent for the water molecule.

\section{Formation of unprotonated $\left(\mathrm{SO}_{2}\right)_{n} \mathrm{H}_{2} \mathrm{O}$ clusters}

The photon absorption cross sections of $\mathrm{H}_{2} \mathrm{O}$ and $\mathrm{SO}_{2}$ are $18 \times 10^{-18}$ (Ref. 32) and $12 \times 10^{-18} \mathrm{~cm}^{2},{ }^{33}$ respectively, at $26.5 \mathrm{eV}$ photon energy. Both $\mathrm{SO}_{2}(\mathrm{IE}=12.6 \mathrm{eV})^{3}$ and $\mathrm{H}_{2} \mathrm{O}$ $(12.74 \mathrm{eV})^{34}$ can function as the ionized molecular species in the cluster. Following ionization the charge can remain in either moiety and transfer between the two. The proton affinity of $\mathrm{SO}_{2}$ and $\mathrm{H}_{2} \mathrm{O}$ are 6.97 and $7.17 \mathrm{eV}$, respectively. ${ }^{35}$ The proton affinity of water increases with increasing cluster size. For the mixed cluster $\left(\mathrm{SO}_{2}\right)\left(\mathrm{H}_{2} \mathrm{O}\right)_{n}(n \geqslant 2)$, after ionization of $\mathrm{H}_{2} \mathrm{O}$, the charge will stay on one water molecule and a proton will transfer to another water molecule, generating the mixed cluster ions $\left(\mathrm{SO}_{2}\right)\left(\mathrm{H}_{2} \mathrm{O}\right)_{n} \mathrm{H}^{+}(1 \leqslant n \leqslant 6)$ observable in the mass spectrum for low pressure, $5 \%$ $\mathrm{SO}_{2} / \mathrm{H}_{2} \mathrm{O} / \mathrm{He}$ expansions.

Theory and experiment give a stable $\left(\mathrm{H}_{2} \mathrm{O}\right)\left(\mathrm{SO}_{2}\right)$ cluster with a binding energy of ca. $3.5 \mathrm{kcal} / \mathrm{mol}$ (Ref. 10) and a planar $\mathrm{SO}_{2}$ and $\mathrm{H}_{2} \mathrm{O}$ stacked on each other in a nonhydrogen-bonded structure. The two molecular planes are at an angle of about $45^{\circ}$ to one another. ${ }^{8}$ Thus a barrier to proton transfer may well exist in the mixed dimer. Femtosecond ionization spectra show that the $\left(\mathrm{SO}_{2}\right) \mathrm{H}^{+}$ion is detected from the ionization of the mixed neutral dimer $\left(\mathrm{SO}_{2}\right)\left(\mathrm{H}_{2} \mathrm{O}\right) \cdot{ }^{12,13,21}$

In the present experiment with $26.5 \mathrm{eV}$ ionization, obvious signals of the unprotonated mixed dimer ion $\left(\mathrm{SO}_{2}\right)$ $\times\left(\mathrm{H}_{2} \mathrm{O}\right)^{+}$(Fig. 5) and mixed $\left(\mathrm{SO}_{2}\right)_{n}\left(\mathrm{H}_{2} \mathrm{O}\right)^{+}$ions $(1 \leqslant n \leqslant 5)$ (Fig. 7) are observed. Two possible channels for $\left(\mathrm{SO}_{2}\right)$ $\times\left(\mathrm{H}_{2} \mathrm{O}\right)^{+}$generation are

$$
\left(\mathrm{SO}_{2}\right)\left(\mathrm{H}_{2} \mathrm{O}\right)+h \nu \rightarrow\left(\mathrm{SO}_{2}\right)\left(\mathrm{H}_{2} \mathrm{O}\right)^{+}+e^{-} \quad(\text { channel } \mathrm{A}),
$$




$$
\begin{aligned}
\left(\mathrm{SO}_{2}\right)_{m} \mathrm{H}_{2} \mathrm{O}+h \nu \rightarrow & \left(\mathrm{SO}_{2}\right)\left(\mathrm{H}_{2} \mathrm{O}\right)^{+}+e^{-} \\
& \left.+(m-1) \mathrm{SO}_{2} \quad \text { (channel } \mathrm{B}\right) .
\end{aligned}
$$

$\left(\mathrm{SO}_{2}\right)\left(\mathrm{H}_{2} \mathrm{O}\right)^{+}$is generated directly from the mixed neutral cluster upon ionization in channel A. $\left(\mathrm{SO}_{2}\right)\left(\mathrm{H}_{2} \mathrm{O}\right)^{+}$is generated from the mixed neutral cluster $\left(\mathrm{SO}_{2}\right)_{n}\left(\mathrm{H}_{2} \mathrm{O}\right)$ in channel B. Excess energy deposited in the cluster by the laser photon (energy above AIE) is removed from the cluster by the loss of $(m-1) \mathrm{SO}_{2}$ molecules in channel $\mathrm{B}$ to generate $\left(\mathrm{SO}_{2}\right)$ $\times\left(\mathrm{H}_{2} \mathrm{O}\right)^{+}$. This behavior is observed in the study of water clusters in a $20 \% \mathrm{Ar} / \mathrm{He}$ expansion gas. ${ }^{14}$ The signal intensity for $\left(\mathrm{H}_{2} \mathrm{O}\right)_{2}^{+}$dimer ion is larger than that of the protonated $\mathrm{H}_{3} \mathrm{O}^{+}$ion, generated in a $\mathrm{He}$ expansion by proton transfer and fragmentation of the $\left(\mathrm{H}_{2} \mathrm{O}\right)_{2}^{+}$initial ion. Similar results are obtained for $\mathrm{CO}_{2} \cdot \mathrm{H}_{2} \mathrm{O}$ clusters studied in our laboratory. ${ }^{31}$ Nonetheless, no unprotonated water clusters are observed in either $5 \%$ or $20 \% \mathrm{SO}_{2} / \mathrm{H}_{2} \mathrm{O} / \mathrm{He}$ expansions at any backing pressure. As we have argued above, $\left(\mathrm{H}_{2} \mathrm{O}\right)_{n} \mathrm{H}^{+}$ ions detected in mixed systems $\left(5 \% \mathrm{SO}_{2} / \mathrm{H}_{2} \mathrm{O} / \mathrm{He}\right.$ expansion) are not generated from $\left(\mathrm{SO}_{2}\right)_{m}\left(\mathrm{H}_{2} \mathrm{O}\right)_{n}$ clusters by loss of $\mathrm{SO}_{2}$ molecules. Thus we find that under our experimental conditions $\left(\mathrm{SO}_{2}\right)\left(\mathrm{H}_{2} \mathrm{O}\right)^{+}$is generated directly from $\left(\mathrm{SO}_{2}\right)$ $\times\left(\mathrm{H}_{2} \mathrm{O}\right)$.

The VIE for $\left(\mathrm{H}_{2} \mathrm{O}\right)_{2}$ is higher than the appearance potential of $\mathrm{H}_{3} \mathrm{O}^{+}+\mathrm{OH}^{36}$ Thus the proton transfer reaction almost always occurs after ionization of the neutral water dimer. Protonated water clusters thereby dominate the mass spectrum for a pure $\mathrm{H}_{2} \mathrm{O} / \mathrm{He}$ expansion and only a very weak signal for $\left(\mathrm{H}_{2} \mathrm{O}\right)_{2}^{+}$is observed with $26.5 \mathrm{eV}$ single photon ionization. ${ }^{14}$ Proton transfer can occur for the mixed dimer $\left(\mathrm{SO}_{2}\right)\left(\mathrm{H}_{2} \mathrm{O}\right)$ after ionization as well, by the following reaction:

$\left(\mathrm{SO}_{2}\right)\left(\mathrm{H}_{2} \mathrm{O}\right)+h \nu \rightarrow\left\{\left(\mathrm{SO}_{2}\right)\left(\mathrm{H}_{2} \mathrm{O}\right)^{+}\right\}^{*} \rightarrow \mathrm{SO}_{2} \mathrm{H}^{+}+\mathrm{OH}+e^{-}$.

The proton affinity of $\mathrm{OH}(5.74 \mathrm{eV})$ is clearly smaller than that of $\mathrm{SO}_{2}(6.97 \mathrm{eV}) .{ }^{35}$ But the $\mathrm{SO}_{2} \cdot \mathrm{H}_{2} \mathrm{O}$ complex is a nonhydrogen-bonded structure and more energy is probably required for the proton transfer reaction relative to the hydrogen bond $\left(\mathrm{H}_{2} \mathrm{O}\right)_{2}$ structure. In the present experiment, most if not all of the energy of the $26.5 \mathrm{eV}$ ionization photon above the cluster VIE is removed by the exiting electron. Independent of the moiety in the mixed $\left(\mathrm{SO}_{2}\right) \cdot\left(\mathrm{H}_{2} \mathrm{O}\right)$ dimer that is ionized, the charge probably remains on that species (for Franck-Condon reason) as the energy remaining in the cluster after ionization is insufficient to surmount the barrier to charge and proton transfer. Even as the proton affinity of the $\left(\mathrm{SO}_{2}\right)_{n}$ moiety of the $\left(\mathrm{SO}_{2}\right)_{n} \mathrm{H}_{2} \mathrm{O}$ cluster increases with increasing $n$, only unprotonated $\left(\mathrm{SO}_{2}\right)_{n} \mathrm{H}_{2} \mathrm{O}^{+}$clusters are detected (see Fig. 7).

The mixed dimer $\left(\mathrm{SO}_{2}\right)\left(\mathrm{H}_{2} \mathrm{O}\right)$ has an isomer $\mathrm{H}_{2} \mathrm{SO}_{3}$. Calculations indicate that the barrier to this isomerization is high $(37 \mathrm{kcal} / \mathrm{mol})$. Thermodynamic studies find an autocatalytic effect for the decomposition of $\mathrm{H}_{2} \mathrm{SO}_{3}$ : this implies that additional water molecules can act as a catalyst to lower the reaction barrier for $\mathrm{H}_{2} \mathrm{SO}_{3} \rightarrow \mathrm{SO}_{2}+\mathrm{H}_{2} \mathrm{O}$. In these experi- ments the mixed dimer is formed in the beam, but during the expansion process $\left(\mathrm{SO}_{2}\right)\left(\mathrm{H}_{2} \mathrm{O}\right)$ does not have enough energy to convert to the $\mathrm{H}_{2} \mathrm{SO}_{3}$ molecule.

\section{CONCLUSIONS}

The van der Waals clusters $\left(\mathrm{SO}_{2}\right)_{n}$ and $\left(\mathrm{SO}_{2}\right)_{m}\left(\mathrm{H}_{2} \mathrm{O}\right)_{n}$ are investigated by $26.5 \mathrm{eV}$ single photon ionization and TOFMS detection. The distribution of $\left(\mathrm{SO}_{2}\right)_{n}$ clusters decreases roughly exponentially with increasing cluster size $n$. The loss of one $\mathrm{SO}_{2}$ molecule from the cluster ion $\left(\mathrm{SO}_{2}\right)_{n}^{+}$is observed with a reflectron TOFMS. Metastable dissociation rate constants for $\left(\mathrm{SO}_{2}\right)_{n}^{+}$to yield $\left(\mathrm{SO}_{2}\right)_{n-1}^{+}$are in the range of $(0.6-1.5) \times 10^{4} \mathrm{~s}^{-1}$ for cluster sizes $5 \leqslant n \leqslant 16$. This is the same range as found for similar rate constants for water, methanol, and ammonia cluster ions. A minor fragmentation path (loss of $\mathrm{O}$ atom) for the cluster ions is identified but this process is found to decrease with increasing cluster size.

Mixed $\mathrm{SO}_{2} \cdot \mathrm{H}_{2} \mathrm{O}$ clusters are studied under different cluster generation conditions and the predominant signals in the mass spectra are due to $\left(\mathrm{H}_{2} \mathrm{O}\right)_{n} \mathrm{H}^{+}$and $\left(\mathrm{SO}_{2}\right)_{n}^{+}$cluster ions as a function of conditions (concentration, expansion pressure). Mixed clusters of the form $\left(\mathrm{SO}_{2}\right)\left(\mathrm{H}_{2} \mathrm{O}\right)_{n} \mathrm{H}^{+}$and $\left(\mathrm{SO}_{2}\right)_{n} \mathrm{H}_{2} \mathrm{O}^{+}$are also observed at low intensities. $\mathrm{SO}_{2}$ and $\mathrm{H}_{2} \mathrm{O}$ are not good solvents for one another. Unprotonated mixed cluster ions $\left(\mathrm{SO}_{2}\right)_{n} \mathrm{H}_{2} \mathrm{O}^{+}(1 \leqslant n \leqslant 5)$ are observed at high $\mathrm{SO}_{2}$ concentration and $\left(\mathrm{SO}_{2}\right)\left(\mathrm{H}_{2} \mathrm{O}\right)_{n} \mathrm{H}^{+}$are observed at low $\mathrm{SO}_{2}$ concentration. Proton transfer between $\mathrm{H}_{2} \mathrm{O}$ and $\mathrm{SO}_{2}$ in mixed clusters has a high activation energy.

\section{ACKNOWLEDGMENT}

This research has been supported in part by the NSF ERC for Extreme Ultraviolet Science and Technology under NSF Award No. 0310717. Other support from this work comes from the U.S. DOE, NSF, and Philip Morris U.S.A.

${ }^{1}$ F. Y. Leung, A. J. Colussi, and M. R. Hoffmann, J. Phys. Chem. A 105, 8073 (2001).

${ }^{2}$ J. J. Margitan, J. Phys. Chem. A 101, 9778 (1997).

${ }^{3}$ J. Erickson and C. Y. Ng, J. Chem. Phys. 75, 1650 (1981).

${ }^{4}$ A. Taleb-Bendiab, K. W. Hilling II, and R. L. Kuczkowski, J. Chem. Phys. 94, 6956 (1991).

${ }^{5}$ K. L. Knappenberger, Jr. and A. W. Castleman, Jr., J. Chem. Phys. 121, 3540 (2004).

${ }^{6}$ A. F. Voegele, C. S. Tautermann, C. Rauch, T. Loerting, and K. R. Liedl, J. Phys. Chem. A 108, 3859 (2004).

${ }^{7}$ W. K. Li and M. L. Mckee, J. Phys. Chem. A 101, 9778 (1997).

${ }^{8}$ K. Matsumura, K. J. Lovas, and R. D. Suenram, J. Chem. Phys. 91, 5887 (1989).

${ }^{9}$ A. Schriver, L. Schriver, and J. P. Perchard, J. Mol. Spectrosc. 127, 125 (1988).

${ }^{10}$ W. K. Li and M. L. Mckee, J. Phys. Chem. A 101, 9778 (1997).

${ }^{11}$ E. Bishenden and D. J. Donaldson, J. Phys. Chem. A 102, 4638 (1998).

${ }^{12}$ K. L. Knappenberger, Jr. and A. W. Castleman, Jr., J. Chem. Phys. 122, 154306 (2005).

${ }^{13}$ T. E. Dermota, D. P. Hydutsky, N. J. Bianco, and A. W. Castleman, Jr., J. Phys. Chem. A 109, 8254 (2005).

${ }^{14}$ F. Dong, S. Heinbuch, J. J. Rocca, and E. R. Bernstein, J. Chem. Phys. 124, 224319 (2006).

${ }^{15}$ S. Heinbuch, M. Grisham, D. Martz, and J. J. Rocca, Opt. Express 13, 4050 (2005).

${ }^{16} \mathrm{http}: / /$ rmjordan.com/resources/Tutorial.pdf

${ }^{17}$ S. Wei, W. B. Tzeng, and A. W. Castleman, Jr., J. Chem. Phys. 92, 332 (1990).

${ }^{18}$ H. Shiromaru, N. Nishi, and N. Washida, J. Chem. Phys. 84, 5561 
(1986); H. Shinohara and N. Nishi, ibid. 83, 1939 (1985); H. Fu, Y. J. Hu, and E. R. Bernstein, ibid. 124, 024302 (2006).

${ }^{19}$ S. M. Hurley, T. E. Dermota, D. P. Hydutsky, and A. W. Castleman, Jr., J. Phys. Chem. A 107, 3497 (2003).

${ }^{20}$ T. E. Dermota, D. P. Hydutsky, N. J. Bianco, and A. W. Castleman, Jr., J. Phys. Chem. A 109, 8259 (2005).

${ }^{21}$ Q. Zhong, S. M. Hurley, and A. W. Castleman, Jr., Int. J. Mass. Spectrom. 185/186/187, 905 (1999).

${ }^{22}$ D. J. Donaldson, V. Vaida, and R. Naaman, J. Phys. Chem. 92, 1204 (1988).

${ }^{23}$ D. J. Donaldson, V. Vaida, and R. Naaman, J. Phys. Chem. 87, 2522 (1987).

${ }^{24}$ A. Kanaev, L. Museur, F. Edery, T. Laarmann, and T. Möller, J. Chem. Phys. 117, 9423 (2002).

${ }^{25}$ M. F. Hineman, E. R. Berstein, and D. F. Kelley, J. Chem. Phys. 94, 2516 (1993).

${ }^{26}$ M. F. Hineman, S. K. Kim, E. R. Berstein, and D. F. Kelley, J. Chem.
Phys. 92, 4904 (1991).

${ }^{27}$ J. Yao, J. A. Fernandez, and E. R. Bernstein, J. Chem. Phys. 107, 8813 (1997).

${ }^{28}$ P. M. Felker and A. H. Zewail, Adv. Chem. Phys. 70, 265 (1988).

${ }^{29}$ T. S. Julius, X. Xin, and A. G. William, J. Phys. Chem. A 108, 10518 (2004).

${ }^{30}$ I. P. Buffey and W. B. Brown, Chem. Phys. Lett. 109, 59 (1984).

${ }^{31}$ S. Heinbuch, F. Dong, J. J. Rocca, and E. R. Bernstein, J. Chem. Phys. 125, 154316 (2006), preceding paper.

${ }^{32}$ G. N. Haddad and J. A. R. Samson, J. Chem. Phys. 84, 6623 (1986).

${ }^{33}$ H. Hamdy, Z. X. He, and J. A. R. Samson, J. Phys. B 24, 4803 (1991).

${ }^{34}$ L. Karlsson, L. Mattsson, R. Jadrny, R. G. Albridge, S. Pinchas, T. Bergmark, and K. Siegbahn, J. Chem. Phys. 62, 4745 (1975).

${ }^{35}$ CRC Handbook of Chemistry and Physics, 81 st ed., edited by D. R. Lide (CRC, Boca Raton, FL, 2000-2001).

${ }^{36}$ H. Shiromaru, H. Shinohara, and N. Washida, Chem. Phys. Lett. 41, 7 (1987). 